\title{
A Huge Liver Cyst Manifesting Dyspnea and Edema
}

\author{
Satoko Nagao ${ }^{1}$, Masaya Iwamuro ${ }^{2}$, Hidenori Shiraha ${ }^{2}$ and Fumio Otsuka ${ }^{1}$
}

Key words: dyspnea, heart failure, inferior cava vein syndrome, liver cysts and renal failure

(Intern Med 58: 1811-1812, 2019)

(DOI: 10.2169/internalmedicine.1957-18)
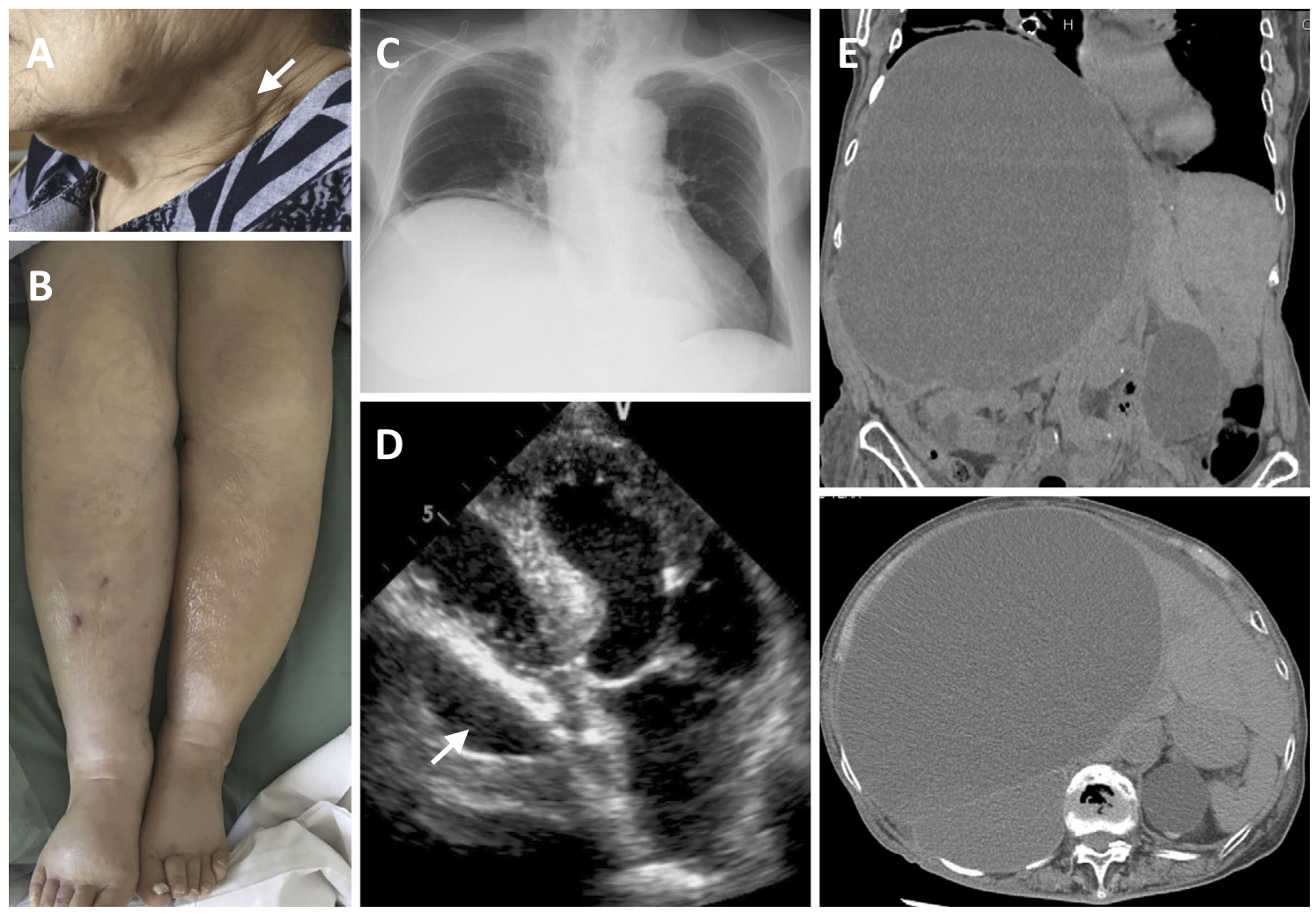

Picture.

An 88-year-old woman with a 2-year history of dyspnea and edema was referred to our hospital. She showed jugular venous dilatation with Kussmaul sign (Picture A), abdominal distension and edema of the lower limbs (Picture B). Blood tests showed hypoxemia (61.2 $\mathrm{mmHg})$, hypercapnia (50.1 $\mathrm{mmHg}$ ) and renal impairment. Chest X-ray showed no congestion despite deviation of the heart and pulmonary vessels (Picture C). The right ventricle was compressed (Picture D), but the ejection fraction was preserved on ultrasound. Computed tomography revealed a giant $(22 \mathrm{~cm})$ hepatic cyst compressing the lung, heart, inferior vena cava, and right kidney (Picture E). After removal of $3 \mathrm{~L}$ of hemorrhagic fluid by percutaneous drainage, the edema and dyspnea disappeared. Intra-cystic injections of minocycline $(200 \mathrm{mg}, 8$ times) were performed and have been effective for the past year. Hepatic cysts are rarely symptomatic (1); however, the possibility should be considered in patients with dyspnea and edema. Adequate drainage and local injection of the sclerotizing agent minocycline can be effective (2).

The authors state that they have no Conflict of Interest (COI).

${ }^{1}$ Departments of General Medicine, Okayama University Hospital, Japan and ${ }^{2}$ Gastroenterology and Hepatology, Okayama University Hospital, Japan

Received: August 9, 2018; Accepted: December 11, 2018; Advance Publication by J-STAGE: February 25, 2019

Correspondence to Dr. Fumio Otsuka, fumiotsu@md.okayama-u.ac.jp 


\section{References}

1. Nicolau PB, Lázaro JL, Viladomiu L, Casabiel XM, Riveiro-Barciela M. Inferior cava vein syndrome and heart compression due to a giant liver cyst. Am J Gastroenterol 112: 984, 2017.

2. Danza FM, Falcione M, Bordonaro V, Infante A, Paladini A, Bonomo L. Minocycline hydrochloride as a soft sclerotizing agent for symptomatic simple renal and hepatic cysts. Eur Rev Med Pharmacol Sci 21: 408-415, 2017.

The Internal Medicine is an Open Access journal distributed under the Creative Commons Attribution-NonCommercial-NoDerivatives 4.0 International License. To view the details of this license, please visit (https://creativecommons.org/licenses/ by-nc-nd/4.0/).

(C) 2019 The Japanese Society of Internal Medicine Intern Med 58: 1811-1812, 2019 